\title{
On the Variability of Scalar Implicature Computation: Evidence from L2 English Adults
}

\author{
Ahmed Khorsheed ${ }^{1 *}$, Sabariah Md. Rashid ${ }^{1 *}$, Vahid Nimehchisalem ${ }^{1}$, Lee Geok Imm ${ }^{1}$, Jessica Price ${ }^{2}$ \\ ${ }^{1}$ Department of English, Universiti Putra Malaysia, Serdang, Selangor, Malaysia \\ ${ }^{2}$ School of Psychology, University of Nottingham Malaysia, Semenyih, Selangor, Malaysia \\ *Corresponding authors \\ E-mail: amkhorsh@gmail.com (Ahmed Khorsheed) \\ E-mail: smrashid@upm.edu.my (Sabariah Md Rashid)
}

\begin{abstract}
When we say that Some people have lungs, we implicate that not all people have lungs. This scalar implicature arises when we produce a weaker expression instead of a stronger one. Studies on bilingual adults suggest that L2 learners, regardless of their proficiency level, are sensitive to under-informative sentences and they exhibit a superior pragmatic ability on a par with monolingual control groups. However, the evidence obtained from these studies is largely one-dimensional stemming from offline tasks that provide limited information about scalar implicature processing. The present study addressed this issue by investigating scalar implicature computation among L2 adults using an online sentence verification paradigm similar to that of Bott and Noveck whereby participants are required to judge the veracity of categorical under-informative sentences. The study also examined how individual differences in personality traits and L2 proficiency level would modulate participants' pragmatic responses and processing times. Our results showed that those with weaker English proficiency tended to be significantly less sensitive to implicatures than those with proficiency advantage. The two proficiency groups also took significantly longer processing times to compute the pragmatic interpretation than the logical interpretation. The results further revealed that the pragmatic responses and their processing slowdowns were influenced by various personality and autistic traits. Our findings provide novel empirical insights into how L2 learners process scalar implicatures, and thus useful implications for the processing theories in experimental pragmatics and second language acquisition.
\end{abstract}

Key words: scalar implicature, processing cost, personality traits, individual differences, L2 proficiency

\section{Introduction}

Human communication is a very complex system that involves more than straight encoding and decoding of messages. Interlocutors sometimes tend to convey far more than what their words literally mean and therefore they create a variety of inferences known as conversational implicatures. According to Grice [1], understanding the meaning of conversational implicatures involves two kinds of processes: (i) decoding the literal meaning of words and clauses, and (ii) deriving interpretations that go far beyond the literal meaning of the utterance. Several processing studies suggest that decoding the literal meaning is reasonably an easy step-process that does not involve an evaluation of what the speaker might have said but did not, but the question how individuals settle on an interpretation for a given implicature remains a subject of controversy in experimental pragmatics [2, 3].

Grice's framework of conversational implicature offers a clear notion of how conversational exchange is governed by rational expectations called "maxims" [4]. These maxims require interlocutors to be cooperative, clear, direct and relevant to the goal of conversation. If the speaker violates any of these conversational maxims in that they provide a meaning that does not serve the goal of conversation, then they will leave a reason for the hearer to entertain the potential underlying meaning of that utterance and make assumptions for the speaker's alternative intended message; namely, generalized conversational implicature. For instance, if the utterance such as "Some parrots are birds" was 
produced by a speaker, the listener would assume that "not all parrots are birds". This proposition is triggered by the use of the lexical item some whose informational strength tends to be of less maximal value than its peers most and all on the same scale [5, 6]. Logically speaking, the term some is compatible with all; some has two interpretations: some-but-not-all and some-and-possibly-all which are in conflict [7]. However, if the speaker had really meant all, he would have said All parrots are birds, being more informative.

It is worth noting that Grice's distinction between "what is said" and "what is conversationally implicated" was originally to stave off certain ordinary-language arguments against particular philosophical positions and questions; and therefore, his original account was not made to provide specifics about how scalar implicatures are represented prior to their manifestation in real time experimental settings [8]. Grice's conversational framework was yet seen as a useful philosophical tool that has brought lots of new insights that were later developments in the cognitive processing pragmatics [8,9]. The gap between the classical view of the philosopher Grice and the modern outlook of psycholinguists about how scalar implicatures are processed in real time experiments has been later bridged by two main processing approaches that envisage two opposing views about the way in which scalar implicatures are computed; namely, the default theory [10] and the relevance theory [11].

According to the default theory, scalar inferences arrive by default without processing costs. On hearing a sentence such as Some parrots are birds, the first interpretation that is immediately given rise to is the pragmatic interpretation, some [but not all]. The logical interpretation some [and possibly all] can arise only if the implicature is cancelled by contextual information. In cancellation, the processor must pass through a stage in which the upper-bound meaning is considered and then rejected based on implicit or explicit contextual factors. In such respects, the logical interpretation involves a two-step process, whereas the pragmatic interpretation involves only a one-step process [2] (see also [12] for an alternative explanation). To the contrary of the default theory, the relevance theory holds that scalar inferences do not arrive automatically, but rather depend on the contextual situation [11]. In more technical terms, the pragmatic meaning arrives in a second-step process after the logical meaning was computed and then rejected for pragmatic purposes. As Bott and Noveck [2] propose, the explanations of these two accounts suggest two different predictions on the time course taken to process sentences with scalar terms. The default account predicts more processing times for logical meaning than the pragmatic meaning because the pragmatic meaning arrives in a first-step process, whereas the relevance theory predicts more time for the pragmatic meaning because it is generated in a second step after the logical meaning was processed.

There are numerous processing studies that have investigated the predictions of these two theories in the last two decades but the evidence supporting them remains conflicting. Studies are mainly split into two camps: one supports the default theory and is placing emphasis that scalar implicatures are generated automatically without processing costs (e.g., [13-16]), while the other supports the relevance theory and is placing emphasis that implicatures are latearriving carrying cognitive costs (e.g., [2,12,17-21]). The nature of the cognitive effort observed in computing scalar implicatures is also largely disputed. For example, is it all, or a proportion of it, involved in the inferential process? Are there certain linguistic and logical properties that are taxing the working memory and inflate the processing times independently of the inferential mechanism? There are several speculations which suggest that the cognitive effort observed in computing scalar inferences is not a product of the inferential process but rather a product of various aspects that are dependent upon cognitive resources, such as the application of the Theory of Mind in inferring the speaker's knowledge state (e.g., [22-24]), contrasting and evaluating alternatives (e.g., [19]), the decision to derive the implicature (e.g., $[21,25,26])$, some difficulty inherent in the semantic structure of upper-bound sentences compared to lower-bound sentences (e.g., $[12,16,19,25]$ ), embedded negativity (e.g., [2, 27, 28]), and/ or polarity effects (e.g., [27, 29, 30]), although there is no verdict on which subprocess contributes to memory taxation. 
Current investigations on scalar implicature computation increasingly place emphasis on the underlying causes of variation in responding to under-informative sentences, viz, while some people tend to be consistently pragmatic in their interpretations of under-informative sentences, others tend to be consistently logical and often equivocal [17, 3134]. It is undeniable that there are numerous subtle factors that could induce this variability, including the item choice (i.e., universal vs. categorical sentences [2, 32]), number of fillers [35], language and linguistic skills [36, 37], scale structure $[29,38,39]$, but some propositions suggest that this variation is possibly triggered by a decision that is made at a meta-linguistic level: whether to accept and reject a statement is dependent upon personality and pedantry factors $[26,40]$. For instance, in their seminal work, Nieuwland et al. [41] found that the pragmatically-skilled participants (as indexed by a low score on the Communication subscale in the autism spectrum quotient [42]) tended to perform automatic processing of scalar inferences more than their less skilled peers as indexed by the N400 event-related potential (ERP). During the processing of the trigger word some, the individuals with high pragmatic ability rapidly activated the scalar implicature to immediately participate in the semantic processing, whereas individuals with low pragmatic ability could not instantly access the scalar implicature when encountering the trigger word. Zhao et al. [43] also found that auditory presented under-informative sentences elicited a mismatch negativity (MMN) ERP only in participants with a low score on the two autistic traits communication and social skill. They proposed that people with high pragmatic ability may provide a false response to under-informative statements compared to those with low pragmatic ability. However, these two studies cited above were online ERP studies and many behavioral studies using a sentence verification paradigm failed to find any correlations between participants' rate of pragmatic interpretations and personality traits (e.g., [17, 31]). According to Heyman and Schaeken [17], the strength of online ERP to provide insights into the aspects of cognition is possibly impenetrable with behavioral measures.

\section{Scalar implicatures among bilinguals}

The empirical evidence about how bilingual adults make pragmatic interpretations to scalar implicatures is limited and relatively under-explored (see review for Alatawi [44]). When discussing scalar implicatures comprehension among bilingual adults, Slabakova [45] was the first to directly address implicature understanding among L2 learners. Slabakova tested the extent to which Korean and English L1 speakers and Korean L2 learners with different levels of English proficiency would be sensitive to under-informative sentences under two experimental settings, contextualized vs non-contextualized. In the former condition, the under-informative sentences were provided with a context to enrich the pragmatic meaning, whereas the latter condition comprised under-informative sentences to which the participants have to evaluate and judge them without a context. Slabakova found evidence that her L2 learners rejected the infelicitous sentences more than that in the two native speaker groups in both experimental settings. The Korean $\mathrm{L} 2$ learners were also able to make more pragmatic interpretations in the contextualized setting than the neutral setting (90\% vs 60\%). The performance of the two proficiency groups (intermediate vs advanced) also did not vary according to their proficiency level. Slabakova concluded that scalar implicatures arise by default, and thus inferring the pragmatic meaning is not problematic to L2 learners regardless of their proficiency level (also see $[46,47])$

Slabakova's results have been rather controversial in the literature. The reason for which L2 learners behaved more pragmatically than L1 speakers remains arguable. Is it possible that L2 learners are more aware of infelicity than L1 speakers? However, L2 learners have less processing ability and they are said to be less accurate in their L2 than their L1 (see [48, 49] for reviews). In discussing why L2 learners were more pragmatic than L1 speakers, Slabakova accounted that based on the tenets of the default theory. According to the default account, implicatures arise automatically when encountered. For instance, on an encounter with an infelicitous sentence such as Some cats have ears, the first interpretation that is given rise to is the pragmatic interpretation, some [but not all]. The logical interpretation some [and possibly all] can arise only if the implicature is cancelled by incoming contextual information. In cancellation, the processor passes through a stage in which the pragmatic meaning is considered and then rejected based on contextual factors. According to Slabakova, the cancellation process is arduous and L1 speakers are more capable of cancelling the pragmatic interpretation for the sake of a logical interpretation. 
Inspired by the controversial results of Slabakova [45], Dupuy and colleagues [50] recently compared the performance of French monolinguals to French bilinguals (upper-intermediate). The French bilinguals were tested in both their L1 and L2; and therefore, they took half of the stimuli in their L1 and the other half in their L2 in a within-subject design. Their results revealed that French L2 learners had a higher rate of pragmatic interpretations than that of French monolinguals, but the bilingual participants had an identical proportion of pragmatic responses in their L1 and in their L2. Dupuy et al. explained their bilinguals' outperformance to French monolinguals in the within-subject design based on the assumption that having to switch between two languages makes the participants more aware of pragmatic cues; and therefore, more enhanced pragmatic abilities. In a follow-up experiment, Dupuy et al. tested scalar implicature comprehension using a between subject-design and they found that both French monolinguals and French bilinguals gave a comparable proportion of pragmatic interpretations to scalar implicatures. Their study suggested that Slabakova's explanation of the assumption that L2 learners tend to derive more pragmatic interpretations than L1 speakers does not hold true when the participants are tested in a between-subject design. Dupuy et al. [50] suggested that learning a second language does not enhance pragmatic abilities, but having to switch between two languages makes the participant more aware of pragmatic cues.

Other alternative explantions why L2 learners make pragmatic interpretations in comparable amounts to L1 speakers have been linked to a bilingualism advantage $[46,50]$. There is extensive evidence which suggests that bilingualism enhances the executive control system (e.g., [51-55]), and this enhanced executive control function is thought to assist bilingual individuals to have much easier access to implicature than L1 monolinguals and thus demonstating a higher rate of pragmatic interpretations compared to their L1 peers in these behavioural pragmatic tasks. Siegal et al. tested whether bilingualism would confer an advantage in the ability to draw scalar implicatures among children aged 4 to 6 who were either monolingual in English or Japanese or bilingual in the two languages. The monolingual participants were given the test material in their respective native languages and only in Japanese to the bilingual children. All groups were told a story in which a teddy bear was very good at putting hoops on a pole and then they saw a picture that shows the bear and hoops all were on the pole. Then a puppet described that event by producing an underinformative sentence such as "Some of the hoops on the pole" and the children were asked to evaluate the appropriateness of the description that the puppet gave of the event. Siegal et al. [56] found that bilingual children, despite their lower vocabulary scores in the language of testing, are more advanced than their monolingual peers in showing sensitivity to scalar implicatures. Siegal and colleagues suggested that the source of bilinguals' pragmatic superiority to L1 speakers is not linguistic. Bilingual children's precocious pragmatic development is possibly due to their enhanced executive control skills, or maybe bilingual children develop "heightened pragmatic skills as a compensation of their weaker knowledge of core language" [57].

However, Siegal et al.'s results, which suggest that bilinguals make more pragmatic interpretations than monolinguals as a function of their enhanced executive functioning control, does not seem to be in line with the results reported by Antoniou and Katsos [36]. Similar to Siegal et al.[56], Antoniou and Katsos used a large battery of pragmatic tests that probe into the knowledge of different types of conversational implicature. They used two tasks on scalar implicature comprehension and the maxim of quantity (see Antoniou and Katsos for a detailed description of the tasks). Their study compared the performance of three groups of participants whose years of age range between 6 and 9: (i) monolinguals, (ii) bilectals, and (iii) and multilinguals. Antoniou and Katsos [36] found no statistical difference between bilingual, bilectal, and multilingual children's understanding skills. Multingual and bilectal children exhibited monolingual-like understanding of implicatures; and therefore, there was no multilingual-exclusive pragmatic advantage revealed, consistent with a recent study exploring the pragmatic abilities of Slovenian monolingual and Slovenian-Italian bilingual 10-year-olds [50]. Their results also did not support an effect of executive functioning on children's pragmatic ability. However, participants' proficiency in the language of testing as well as years of age were critical predictors of implicature understanding. Antoniou and Katsos [36] concluded that implicature understanding is a "pragmatic-communicative skill that largely depends on children's language abilities." 
In a nutshell, these previous reports show that the empirical landscape on how bilinguals make pragmatic interpretations of scalar implicatures remains less clear in the literature, specifically whether the superior ability of bilingual adults to make pragmatic interpretations on apar with L1 speakers is due to the automatic processes involved in generating the implicature, to bilingualism advantage, to linguistic proficiency, or to a methodological bias since the majority of evidence supporting their claims exclusively comes from offline judgment tasks. Studies on second language sentence processing suggest that L2 performance is variable across online and offline tasks [58-61]. For instance, Roberts et al. [60] found evidence L2 learners can perform like L1 speakers in offline tasks but they demonstrate inferior performance in online tasks. This study aims to address this issue by investigating scalar implicature comprehension among L2 adults using an online sentence verification paradigm. The study also aims to address the variability in scalar implicature interpretation using an online sentence verification paradigm and measures to participants' language proficiency and personality traits. As a prediction, according to the conclusions made by the previous offline studies, the participants with different language proficiency levels should reveal no behavioral differences. These views are investigated in the present study.

\section{Experiment}

\section{Participants}

The participants were L1 Bahasa Malay undergraduate students from Universiti Putra Malaysia (UPM) with two levels of English proficiency: 116 modest learners of English (age range 18-26, M=22.06, SD=1.8, all females) and 96 competent (age range 18-26, $\mathrm{M}=22.2, \mathrm{SD}=1.4$, all females). Their level of proficiency is determined as gauged by the Malaysian University English Test (MUET) Band 3 and Band 4, respectively. MUET is a localized standard measure of English proficiency utilized by the Malaysian universities for students' admission. The MUET comprises a six-band scale, Band 1 to Band 6. According to the Malaysian Examination Council, students with MUET band 3 are equivalent to those with IELTS band 5, whereas the students with MUET band 4 are equivalent to those with IELTS band 6. The candidates who obtained band 3 are described as modest users of English, whereas the candidates who obtained band 4 are described as competent users of English. All the participants shared a common characteristic that pertains to their ethnic background, that is, the same L1. The reason beyond this sampling condition was to control for their perception of quantification and its informativeness, i.e., participants with different L1 backgrounds may differ in their lexical and syntactic realization of logical quantifiers [62].

\section{Materials}

The study used (i) a truth-value judgment task to examine the extent to which the participants are sensitive to underinformative sentences and (ii) three personality tests to provide an account of their personality style. Greater details on these instruments are given in the following subsections.

\section{Truth-value judgment task}

This is the pragmatic task that assesses the extent to which the participants would derive the pragmatic meaning embedded in under-informative sentences. This task consists of categorical sentences that require participants to provide absolute truth-value judgments using "True" and "False" responses. Capitalizing on Bott and Noveck's test material [2], this task employed 6 types of test sentences, T1 to T6 and 9 instances on each making a total of 54 sentences in the task (see Table 1). The sentences that are labeled as T1 are the experimental sentences that give rise to a scalar implicature, whereas T2 to T6 are only control sentences in the design. 
Table 1. Examples of test sentences

\begin{tabular}{|l|l|c|}
\hline Reference & Example sentence & Appropriate response \\
\hline T1 & Some parrots are birds & True \\
\hline T2 & Some birds are parrots & False \\
\hline T3 & Some parrots are fish & True \\
\hline T4 & All parrots are birds & False \\
\hline T5 & All birds are parrots & False \\
\hline T6 & All parrots are fish & \\
\hline
\end{tabular}

Note. T1 sentence is labeled with a question mark because it can be considered false and sometimes true -this depends on whether the participant draws the inference or not.

Similar to Rips [28] and Bott and Noveck [2], T1, T2 and T3 are statements carrying the same quantifier some but have different category constructions. For instance, T1 and T3 are a case in which the exemplar is the subject of the sentence and the category is the predicate whereas $\mathrm{T} 2$ is a case in which the category is the subject and the exemplar is the predicate. The sentences T4, T5 and T6 have equivalent constructions to that in T1, T2 and T3 respectively, but they employ the quantifier all. T1 sentences are the only sentences that are associated with implicatures and thus are judged false and sometimes true depending on whether the participant draws the inference or not, whereas T2 to T6 are only control sentences that are either patently true or patently false.

It is worth noting that the exemplars and their categories in our study were developed according to the background knowledge of our participants. One reason for this is the fact that the exemplars used in previous studies may not be familiar to the participants of the present study. For instance, in a sentence such as Some haddock are fish from Bott and Noveck, it is possible that the exemplar word haddock may not be known to the participants as an exemplar word that belongs to the Fish family, or that this exemplar is possibly not existent in their world knowledge or L2 knowledge. Therefore, the exemplars of the present study were pre-tested by $35 \mathrm{~L} 1$ Malay undergraduates in a categorization task. They were given a sheet in which there were six categories presented in six columns. The participants were briefed about the task and instructed to list as many representative exemplars of the suggested categories as possible and based on their responses, 9 exemplars from each category were selected to be included in the test materials (see Appendix A).

\section{The Autism Spectrum Quotient (AQ)}

The AQ questionnaire is a self-administered tool that measures the degree to which adults show autism-like traits in their everyday behavior (the AQ; [42]). It comprises 50 questions that assess five key areas: communication, social skill, attention switching, attention to detail, and imagination. Adults with autistic-like behavior are thought to demonstrate either mildly or strongly poor communication skills, poor social skills, poor imagination, strong attention to detail, and poor attention-switching/ strong focus of attention. The present study used this questionnaire to assess the extent to which the participants have autistic traits in their character and whether or not these autistic-related traits would modulate their tendency to derive pragmatic interpretations.

\section{Systemizing Questionnaire (SQ-R)}

The SQ-R is a self-administered questionnaire that measures individual differences in systemizing, i.e., the extent to which one can analyze systems, extract rules, and predict outputs [63, 64]. According to Baron-Cohen [63, 65], systemizing individuals are associated with attention to detail and the seeking of exact truth. The SQ-R has 75 items covering areas known to be associated with social, domestic, mechanical and abstract systems [64]. This study used the SQ-R to measure participants' systemizing skills in order to find out how individual differences in systemizing are likely to be linked to participants' (in)tolerance of pragmatic violations. 


\section{The Big Five Inventory (B5)}

The B5 questionnaire comprises 50 questions that assess 5 dimensions of personality that cover extraversion, agreeableness, conscientiousness, neuroticism, and openness. Extroversion covers facets that pertain to one's being energetic, sociable, adventurous, and enthusiastic; Agreeableness refers to attributes of being sympathetic, helpful, forgiving, and cooperative; Conscientiousness includes characteristics such as being organized, thorough, cautious, and responsible; Neuroticism refers to characteristics such as one getting easily anxious, tense, being unstable, and emotional; and Openness to traits such as being imaginative, intelligent, artistic, and curious (John et al. 2008). We used B5 to examine whether or not the performance in the pragmatic task is influenced by the style of the personality of participants (e.g., $[17,31])$.

\section{Data collection procedure}

The tasks were administered in the following order: the truth-value judgment task, the AQ, the SQ-R, and the B5, respectively. In the truth-value judgment task, the participants were placed in front of a computer and were informed that they had to judge the veracity of categorical sentences by using keyboard buttons labeled True and False, "c" and " $m$ " on a QUERTY keyboard. The task included 54 trials. Each trial in the experiment consisted of a fixation cross and then a presentation to the sentence in the form of words appearing in sequence. The fixation cross remained on the screen for $500 \mathrm{msec}$ and then was replaced by the sentence words that were consecutively flashed onto the screen, one word at a time. Each word remained on the screen for $250 \mathrm{msecs}$, with a gap of $50 \mathrm{msec}$ between each word presented (see Fig 1).

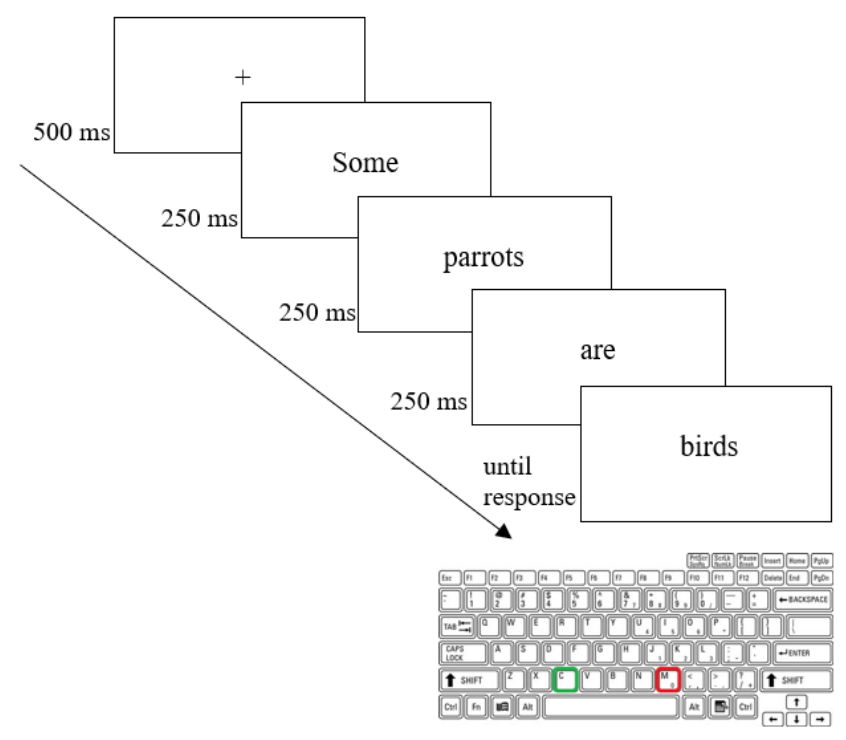

Fig 1. An example of the display of the test sentences including a fixation cross, series of words making up a categorical sentence, and a response keyboard

At the end of the sentence presentation (i.e., sentence reading), the participants were required to evaluate the truth value of their reading and judge as quickly as possible by pressing the green button labeled "True" if they thought the sentence was true or by pressing the red button labeled "False" if they thought the sentence was false. Rejecting T1 sentences corresponds to a pragmatic reading of the under-informative sentences, whereas accepting $\mathrm{T} 1$ sentences corresponds to a logical interpretation, that is, denoting that the participants were not aware of the infelicity of underinformative statements. 
Before starting the experiment, all the participants had a practice session. They saw 18 practice trials with exemplars and categories that were not part of the stimuli in the experimental session. The practice trials also followed the same presentation procedure of the trials in the experimental session. The participants were encouraged to ask questions during the practice session in order to work independently during the experimental session. The experimental session was divided into three blocks in order to give the participants two brief pauses. The participants also saw one dummy sentence at the beginning of each block to avoid problems associated with starting the experimental phase. As regards the design and the order in which the test sentences were presented to participants, a Latin Square design was used to create six lists of sentences so that every exemplar from a category was used only once per list. This procedure was to eliminate, or at least minimize, any adverse effects of frequency and typicality on the reaction times. All participants' responses and reaction times were recorded using E-prime software (version 3.0). They took on average 45 minutes to complete the truth-value judgment task and the other three personality-related questionnaires.

\section{Ethics statement}

The participants were informed that this research was approved by the UPM Research Ethics Committee (reference number: (JKEUPM-2018-197)). Upon task completion, all the participants received a cash payment worth RM10.

\section{Reliability issues}

\section{Personality tests}

Reliability tests were conducted for the AQ, SQ-R, and B5. The overall score of the measures of the internal reliability analysis (Cronbach's $\alpha$ ) was 0.713 for the AQ, 0.908 for the SQ-R, and 0.718 for the B5 questionnaire. The overall Cronbach's Alpha in the three questionnaires was greater than the cut-off point 0.70 , and therefore, the questionnaires met the assumptions of reliability (e.g., [66]).

\section{Experimental timing setup}

The study also examined the reliability of the experimental setup to make sure that the timing of stimulus presentation was acceptable and the participants can read the test sentences without high error rates. The test sentences were presented in the form of words appearing in sequence, one word at a time. Each word remained on the screen for $250 \mathrm{msecs}$, with a gap of $50 \mathrm{msec}$ between each word presented. As a prediction, the timing setup is considered appropriate and not causing any difficulty to the participants if the study obtains high accuracy rates on the control sentences, T2 to T6. High accuracy rates suggest that the participants were able to read and process the sentence meaning and therefore would suggest that the design was reliable. A total of 15 participants took part in this pilot study and the results are given in Table 2 below.

Table 2. Accuracy rates to test sentences

\begin{tabular}{|l|l|l|c|}
\hline Sentence Type & Example & Response & Mean \\
\hline T1 Pragmatic & Some bees are insects & False & $.31(.345)$ \\
\hline T2 & Some insects are bees & True & $.87(.151)$ \\
\hline T3 & Some bees are fish & False & $.96(.070)$ \\
\hline T4 & All bees are insects & True & $.87(.237)$ \\
\hline T5 & All insects are bees & False & $.70(.393)$ \\
\hline T6 & All bees are fish & False & $.97(.051)$ \\
\hline
\end{tabular}

As shown in Table 2 above, there are six types of sentences in the experiment, T1 to T6. T1 sentence was the experimental sentence that requires pragmatic enrichment, whereas $\mathrm{T} 2-\mathrm{T} 6$ were control sentences that are patently true or patently false. It is obvious that the participants were largely accurate on the five control sentences, T2, T3, 
T4, T5 and T6 with accuracy rates that range between $~ 87 \%$ and 97\%, except for the control sentence T5 (70\%), possibly due to difficulty in verifying high-related false superset sentences (e.g., see [67]). These results suggest that the participants were able to provide the right response to each control sentence type: True response for those requiring True, as in T2 and T4, and False response for those requiring False, such as T3, T5 and T6. This suggests that the timing design was appropriate for the participants of the present study and the participants were able to process the sentences and give acceptable rates of correct responses on the control sentences.

\section{Results}

\section{Data treatment}

Prior to data analysis, the gathered data was explored to make certain that it is free from any unwanted outliers. For instance, the participants whose overall accuracy score in judging the truth-value of the control sentences was below $70 \%$ were removed. This procedure resulted in the removal of 7 participants in total: 5 modest and 2 competent users of English. The raw reaction time data were also explored. In the modest English group, all the responses that were faster than $400 \mathrm{~ms}$ and slower than $6 \mathrm{~s}$ after the presentation of the final word were considered outliers and excluded from further analysis, whereas in the competent English group all the responses that were faster than $300 \mathrm{~ms}$ and slower than $6 \mathrm{~s}$ after the presentation of the final word were considered outliers and removed from further analysis. This procedure resulted in the removal of less than $1 \%$ of the reaction time data from each proficiency group. On a trial level, all the trials to which the participants gave error responses in the control condition were also removed and this has eliminated other $12.4 \%$ of the reaction time data in the modest English group and $7.3 \%$ of the reaction time data in the competent English group.

\section{Rate of rejections of under-informative sentences among modest and competent learners of English}

This section analyzes the extent to which our modest and competent English groups make pragmatic interpretations of under-informative sentences. As shown in Table 3, there are six types of sentences, T1 to T6, where T1 was the experimental sentence that requires pragmatic enrichment, whereas T2-T6 were control sentences that are patently true or false and thus requiring no pragmatic enrichment. In order to calculate the mean score for each sentence type in the experiment, the trials for each sentence type were pooled together so as to produce a set of six individual means. The mean and standard deviation for each sentence type are presented in Table 3 and graphically displayed in Fig. 2 below.

Table 3. Choice proportions as a function of sentence type and proficiency level

\begin{tabular}{|l|l|l|c|}
\hline Proficiency level & Test sentence & Example & Mean \\
\hline \multirow{5}{*}{ Modest } & T1-Pragmatic & Some parrots are birds & $.32(.339)$ \\
\cline { 2 - 4 } & T2 & Some birds are parrots & $.87(.190)$ \\
\cline { 2 - 4 } & T3 & Some parrots are fish & $.96(.101)$ \\
\cline { 2 - 4 } & T4 & All parrots are birds & $.91(.159)$ \\
\cline { 2 - 4 } & T5 & All birds are parrots & $.70(.369)$ \\
\cline { 2 - 4 } & T6 & All parrots are fish & $.94(.132)$ \\
\hline \multirow{5}{*}{ Competent } & T1-Pragmatic & Some parrots are birds & $.50(.387)$ \\
\cline { 2 - 4 } & T2 & Some birds are parrots & $.92(.144)$ \\
\cline { 2 - 4 } & T3 & Some parrots are fish & $.97(.060)$ \\
\cline { 2 - 4 } & T4 & All parrots are birds & $.92(.161)$ \\
\cline { 2 - 4 } & T5 & All birds are parrots & $.84(.257)$ \\
\cline { 2 - 4 } & T6 & All parrots are fish & $.98(.060)$ \\
\hline
\end{tabular}




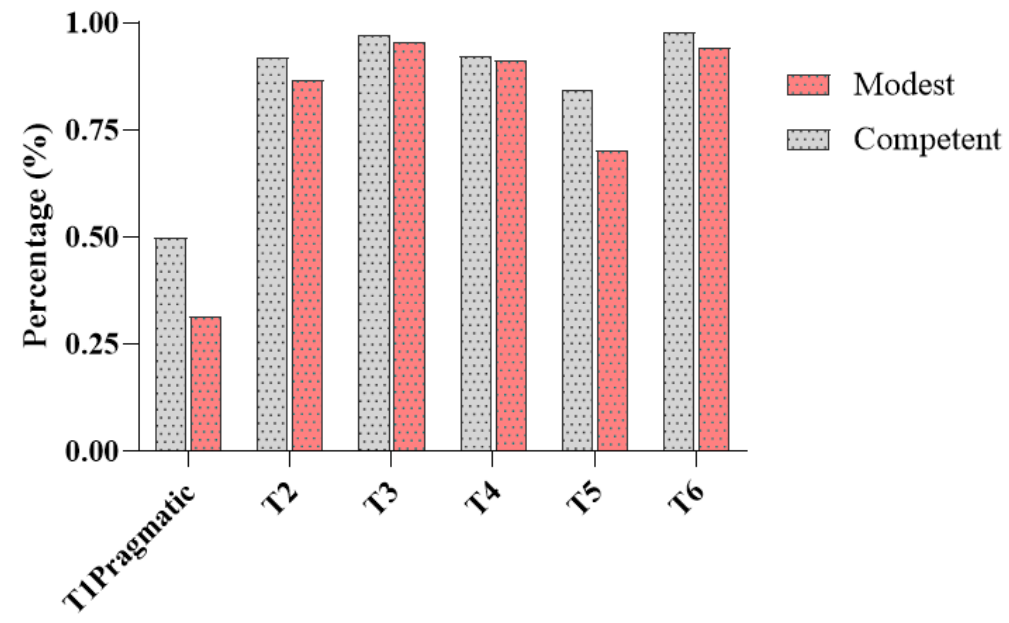

Sentence Type

Fig 2. Choice proportions as a function of sentence type and proficiency level

According to the results in Table 3 above, both groups of participants were largely accurate on the five control sentences, that is, they provided the right response to each control sentence type: True response for those requiring True, as in T2 and T4, and False response for those requiring False, such as T3, T5, and T6. The accuracy rates on the control sentences ranged between $70 \%$ and $96 \%$ in the modest English group, whereas between $87 \%$ and $98 \%$ in the competent English group. These high accuracy rates suggest that the participants complied with the instructions of the experiment and did not respond at random.

As regards the experimental sentence T1-Pragmatic, it is was obvious that the participants with modest English proficiency had weaker tendencies to make pragmatic interpretations of scalar implicatures (32\%) compared to those with competent English (50\%). In order to examine whether this difference was statistically significant, a MannWhitney U Test was conducted. The results of the analysis revealed that the proportion of pragmatic interpretations made by the modest users of English $(M d=22, n=111)$ and competent users of English $(M d=67, n=94)$ was statistically significant $(U=11026.5, z=3.228, p=.001)$. These results provide evidence that the participants with competent English can significantly make more pragmatic interpretations than their peers with modest English skills.

\section{Processing time of pragmatic interpretations of scalar implicatures among modest and competent learners of English}

The study also examined the time taken to make pragmatic interpretations and logical interpretations in each proficiency group. In order to assess whether the time it takes to make a logical interpretation or a pragmatic interpretation is faster, each participant's responses to T1 sentences were divided into T1-Logical and T1-Pragmatic to find the respective mean score for each category. This division allows a within-subject measure of the change in reaction time when the participant makes a logical response or a pragmatic response (i.e., paired-samples $t$-test). The participants who used a single-type response, either completely logical or completely pragmatic to $\mathrm{T} 1$ sentences, were not eligible for this analysis and thus a total of 84 participants were removed from both proficiency groups, 46 participants from the modest English group and 38 participants from the competent English group. 
To run a paired-sample $t$-test to compare the reaction times taken to make pragmatic interpretations and logical interpretations to $\mathrm{T} 1$ sentences, the data were subjected to the test of normality to ensure that the data meet the assumptions of normality required for running a paired-samples $t$-test. The results obtained from Kolmogrov and Shapiro Wilk revealed that the data in T1-Pragmatic and T1-Logical met the assumptions of normality (all $p$ 's >.05). A paired-sample $t$-test was conducted and the results revealed that the time taken to respond pragmatically was significantly longer than the time taken to respond logically regardless of proficiency level, i.e., in the modest English group $(t(64)=6.094, p<0.001)$ and the modest English group $(t(55)=4.737, p<0.001)$.

Similar to Bott and Noveck [2], we also carried out paired-samples $t$ tests between the T1-Pragmatic and each of the control sentences to determine if the time taken to respond pragmatically to $\mathrm{T} 1$ sentences was characteristically different from the time taken to respond to the other control sentences, T2 to T6. If the time to make T1-Pragmatic was characteristically unique, then we should expect to find the reaction times to T1-Pragmatic slower than all the reaction times taken to respond to each control sentence. Before conducting the paired-samples tests, we first logtransformed the raw millisecond reaction times of our data to improve the conformity of the data to the assumptions of normality (Ratcliff, 1993). Subsequent to this, paired-samples $t$ tests between T1-Pragmatic and each of the control sentences were conducted and the results revealed that this was indeed the case. The pragmatic reaction times were significantly longer than those reaction times in the control sentences, in the modest English group (all $t(69)$ 's $>4.83$, all $p$ 's $<.001$ ), and the competent English group ( all $t(70)$ 's $>4.14$, all $p$ 's $<.001$ ).

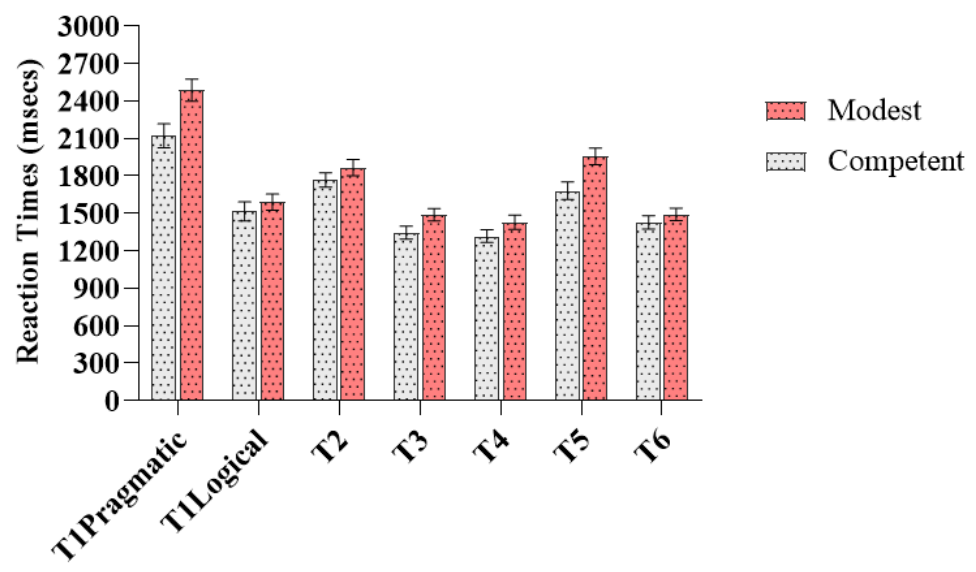

Sentence Type

Fig 3. The reaction times as a function of sentence type and proficiency level. Error bars refer to the standard error of the mean for the relevant cell of the design.

To compare if the time taken to make pragmatic interpretations between the two proficiency groups was statistically significant, an independent-sample $t$-test was conducted. The differences in variability between the two groups was confirmed equal by Levene's test $(p=.490)$. The results revealed that the competent English group made the pragmatic interpretations significantly faster $(M=2120.36, S D=810.52)$ than their less proficient peers $(M=2485.67, S D=$ $736.46),(t(139)=2.80, p=.006$, two-tailed $)$. This processing slowdown is also orthogonal to T-Pragmatic interpretations as the results did not reveal any significant differences between the modest group and competent group in the time taken to make T1-Logical $(t(183)=.727, p>.05$, two-tailed). These results provide evidence that making the pragmatic interpretations of scalar implicatures is more cognitively demanding to the modest users of English than their competent peers. 


\section{Relationship between personality traits and rate of rejections of under-informative sentences}

\section{Modest English group}

The study assessed the relationship between participants' personality traits and the rate of rejections of underinformative sentences using multiple regression. However, for exploratory purposes (similar to the procedures applied by Antoniou et al. [31]), we first conducted bivariate and partial correlation analyses on the grounds that not all the tested independent variables (11) would explain the dependent variable, and that adding many redundant variables to the regression model may bring a statistical noise [66]. Our bivariate correlation analyses of the data revealed that only two variables were correlated with the participants' proportion of pragmatic interpretations; namely, the trait attention to detail was significantly and negatively correlated $(r$ (two-tailed) $=-.26$, bootstrap 95\% CI [-.419, -.085]) and trait Systemizing was significantly and positively correlated $(r$ (two-tailed $)=.26$, bootstrap 95\% CI [ .077, .412]). When the variables attention to detail and systemizing were controlled for using partial correlations, the results indicated no significant correlations between the personality trait measures and participants' proportion of pragmatic interpretations

To further explore how these two variables attention to detail and systemizing predict the outcome variable, a regression analysis was conducted. The analysis included these two variables together with the variables that are significantly intercorrelated with them in order to partial out the shared variance between these variables. These were the trait consciousness for attention to detail $(r$ (two-tailed $)=.32$, bootstrap 95\% CI [.157, .478]), and openness for systemizing $(r$ two-tailed $)=.28$, bootstrap 95\% CI [.097, .440] $)$. These four independent variables were entered in a single block using the forced entry method and the bootstrap robust procedure in SPSS. The results obtained from the regression analysis are shown in Table 4 below.

Table 4. Results of bootstrap multiple regression analysis between personality traits and rate of pragmatic interpretations for the modest English group

\begin{tabular}{|l|l|l|l|l|}
\hline Predictor & $\boldsymbol{B}$ & $\boldsymbol{S E}^{a}$ & $\boldsymbol{\beta}$ & Sig $^{\boldsymbol{b}}$ \\
\hline (Constant) & -.63 & .321 & & .849 \\
\hline Attention to Detail & -.054 & .015 & -.324 & .003 \\
\hline Systemizing & .007 & .002 & .292 & .007 \\
\hline Openness & .007 & .009 & .071 & .501 \\
\hline Conscientiousness & -.001 & .007 & -.005 & .961 \\
\hline
\end{tabular}

Note. $R^{2}=.165 ;$ F-test $=5.255\left(p=.001^{\mathrm{c}}\right)$

${ }^{a}$ Standard errors bootstrapped $(\mathrm{BCa})$

${ }^{\mathrm{b}}$ Significance tests bootstrapped (BCa)

${ }^{\mathrm{c}}$ The F-ratio and corresponding $p$ value are for the parametric, non-bootstrap multiple regression analysis. SPSS does not provide bootstrap results for the ANOVA analysis that tests the overall significance of the model.

As shown in Table 4, the overall regression model was significant $(F(4,106)=5.255, p=.001)$, accounting for $16.5 \%$ of the variance in the dependent variable -proportion of pragmatic interpretations. The two predictor variables attention to detail and systemizing also appear the only two independent variables that are statistically significant towards the dependent variable, with the trait attention to detail recording a higher beta value and negative correlation $(t(106)=-3.39, p<.05$, bootstrap estimates) than the positively-correlated systemizing trait $(t(106)=3.06, p<.05$, bootstrap estimates). 


\section{Competent English group}

Similar analytical procedures were applied on the data obtained from the competent English group. Bivariate and partial correlation analyses were run to explore the data before running a regression analysis. The bivariate correlation analyses revealed three variables correlated with the proportion of pragmatic interpretations of scalar implicatures: Social Skill being significantly and negatively correlated $(r$ (two-tailed) $=-.35$, bootstrap 95\% CI [-.518, -.167$])$, Communication being significantly and negatively correlated $(r$ two-tailed $)=-.22$, bootstrap 95\% CI [-.421, -.010]), and Imagination being significantly and negatively correlated $(r$ (two-tailed $)=-.32$, bootstrap 95\% CI [-.484, -.131]). The partial correlation tests did not show any significant relationships between the independent variables and dependent variable when the trait social skill and imagination were controlled for.

To further explore how the three variables social skill, communication, and imagination predict the outcome variable, a regression analysis was conducted. The analysis included these two variables together with the variables that were significantly intercorrelated with them in order to partial out the shared variance between these variables. These included Communication $(r$ (two-tailed $)=.46$, bootstrap 95\% CI $[.287, .587] \mathrm{c})$, Extraversion $(r$ (two-tailed $)=-.33$, bootstrap 95\% CI [ $-.525, .129]$ ) for the Social Skill, and none for the other variables. Using the forced entry method in multiple regression, all four independent variables were entered in a single block using the forced entry method and the bootstrap robust procedure in SPSS. The results obtained from the regression analysis are given in Table 5 below.

Table 5. Results of bootstrap multiple regression analysis between personality traits and rate of pragmatic interpretations for the competent English group

\begin{tabular}{|l|c|c|c|c|}
\hline \multicolumn{1}{|c|}{ Predictor } & $\boldsymbol{B}$ & $\boldsymbol{S E}^{\boldsymbol{a}}$ & $\boldsymbol{\beta}$ & Sig $^{\boldsymbol{b}}$ \\
\hline (Constant) & 1.061 & .186 & & .001 \\
\hline Social Skill & -.051 & .017 & -.306 & .005 \\
\hline Imagination & -.052 & .019 & -.250 & .008 \\
\hline Extraversion & -.006 & .006 & -.089 & .343 \\
\hline Communication & -.011 & .020 & -.061 & .582 \\
\hline
\end{tabular}

Note. $R^{2}=.20 ;$ F-test $=5.53 ;\left(p=.001^{\mathrm{c}}\right)$

${ }^{a}$ Standard errors bootstrapped $(\mathrm{BCa})$

${ }^{\mathrm{b}}$ Significance tests bootstrapped $(\mathrm{BCa})$

${ }^{\mathrm{c}}$ The F-ratio and corresponding $\mathrm{p}$ value are for the parametric, non-bootstrap multiple regression analysis.

SPSS does not provide bootstrap results for the ANOVA analysis that tests the overall significance of the model.

As shown in Table 5, the overall regression model is significant $(F(4,89)=5.53, p=.001)$, accounting for $20 \%$ of the variance in the dependent variable -rate of pragmatic interpretations. The results also show only two variables that significantly predict the proportion of pragmatic interpretations. These are the Social Skill $(t(89)=-2.70, p<.01$, bootstrap estimates) and Imagination $(t(89)=-2.58, p<.01$, bootstrap estimates) being significantly and negatively correlated with the proportion of pragmatic interpretations.

\section{Relationship between personality traits and processing time of pragmatic interpretations}

\section{Modest English group}

Bivariate and partial correlation analyses were first applied to explore the relationships between each personality trait of the participants and the time taken to make pragmatic interpretations. The results obtained from the Pearson Product-Moment correlation analysis revealed two significant independent variables predicting the reaction times to pragmatic interpretations; namely, Neuroticism being significantly and positively correlated ( $r$ (two-tailed) $=.47$, bootstrap 95\% CI $[.289, .613])$, and Extraversion being significantly and negatively correlated ( $r$ (two-tailed) $=-.34$, 
bootstrap 95\% CI [ $-.512,-.141])$. However, the partial correlation analyses did not show any significant correlations between other personality traits with the dependent variable.

In order to examine how these two variables neuroticism and extraversion predict the outcome variable, a regression analysis was conducted. The analysis included these two variables together with the variables that significantly intercorrelated with them so as to partial out the shared variance between these variables. These were the trait Consciousness ( $r$ (two-tailed) $=-.44$, bootstrap 95\% CI [ -.653, -.197] $)$ and Attention Switching $(r$ (two-tailed) $=.28$, bootstrap 95\% CI $[.068, .474])$ for Neuroticism, and the trait Social Skill $(r$ (two-tailed) $=-.62$, bootstrap 95\% CI [ $.747,-.431])$ and Openness $(r$ (two-tailed $)=.29$, bootstrap 95\% CI $[.060, .499])$ for Extraversion. All these variables were entered in one single block with the bootstrap command and forced entry method in SPSS. The results obtained from the regression analysis are presented in Table 6 below.

Table 6. Results of bootstrap multiple regression analysis between personality traits and pragmatic processing time for the modest English group

\begin{tabular}{|l|l|l|l|l|}
\hline Predictor & $\boldsymbol{B}$ & $\boldsymbol{S E}^{\boldsymbol{a}}$ & $\boldsymbol{\beta}$ & Sig $^{\boldsymbol{b}}$ \\
\hline (Constant) & 905.903 & 1164.698 & & .426 \\
\hline Neuroticism & 65.230 & 20.303 & .480 & .003 \\
\hline Extraversion & -28.767 & 22.407 & -.180 & .176 \\
\hline Conscientiousness & 19.331 & 18.042 & .125 & .255 \\
\hline Openness & -16.911 & 46.068 & -.050 & .708 \\
\hline Social Skill & 9.405 & 20.556 & .050 & .637 \\
\hline Attention Switching & -34.949 & 45.365 & -.081 & .437 \\
\hline
\end{tabular}

Note. $R^{2}=.25 ; \mathrm{F}$-test $=3.548\left(p=.004^{\mathrm{c}}\right)$

${ }^{a}$ Standard errors bootstrapped $(\mathrm{BCa})$

${ }^{\mathrm{b}}$ Significance tests bootstrapped (BCa)

${ }^{\mathrm{c}}$ The F-ratio and corresponding $\mathrm{p}$ value are for the parametric non-bootstrap multiple regression analysis. SPSS does not provide bootstrap results for the ANOVA analysis that tests the overall significance of the model.

The results in Table 6 show only one independent variable that predicts the processing times of pragmatic interpretations for modest users of English; namely, Neuroticism being positive and significant $(t(63)=3.35, p=.003$, bootstrap estimates). This suggests that participants who score high in neuroticism tend to exhibit increased reaction times in making the pragmatic interpretations.

\section{Competent English group}

The bivariate correlation analyses between the personality traits and the reactions times to pragmatic responses revealed that the trait neuroticism was the only independent variable that was significantly and positively correlated with the time taken to make pragmatic interpretations by the competent users of English ( $r$ (two-tailed) $=.46$, bootstrap 95\% CI $[.252, .249])$. In the partial correlation, after controlling for the traits neuroticism, social skill, extraversion, and openness, the results showed that the trait communication was significantly and positively correlated with the dependent variable $(r$ (two-tailed) $=.31$, bootstrap 95\% CI $[.073, .505])$. However, when controlling for all the independent variables of the study, the trait openness appeared significantly and negatively correlated with the dependent variable $(r$ (bivariate, two-tailed $)=-.25$, bootstrap 95\% CI $[-.466,-.050])$.

In order to further examine how the variables neuroticism, communication and openness predict the reaction times to make pragmatic responses to under-informative sentences, a regression analysis was conducted. The analysis included these three independent variables and the variables that intercorrelated with them in order to partial out the variance between these variables. These included agreeableness ( $r$ (bivariate, two-tailed) $=-.31$, bootstrap 95\% CI [ -.082, - 
$.524])$ and consciousness ( $r$ (bivariate, two-tailed $)=-.24$, bootstrap 95\% CI [ -.001, -.471]) for trait neuroticism, and social skill $(r($ bivariate, two-tailed $)=.29$, bootstrap 95\% CI $[.008, .517])$ and extraversion $(r$ (bivariate, two-tailed $)=$ -.33 , bootstrap $95 \%$ CI $[-.595,-.014]$ ) for trait communication. Using the forced entry method in multiple regression analysis, all these variables were entered in a single block with the bootstrap robust procedure in SPSS. A summary of the regression results is given in Table 7.

Table 7. Results of bootstrap multiple regression analysis between personality traits and pragmatic processing time for the competent English group

\begin{tabular}{|l|r|r|r|r|}
\hline \multicolumn{1}{|c|}{ Predictor } & $\boldsymbol{B}$ & \multicolumn{1}{|c|}{$\boldsymbol{S E}^{\mathrm{a}}$} & $\boldsymbol{\beta}$ & Sig $^{\boldsymbol{b}}$ \\
\hline (Constant) & 1120.403 & 879.959 & & .192 \\
\hline Neuroticism & 57.772 & 15.434 & .440 & .001 \\
\hline Communication & 130.041 & 47.178 & .322 & .008 \\
\hline Openness & -39.765 & 16.681 & -.232 & .015 \\
\hline Agreeableness & 27.092 & 22.057 & .167 & .222 \\
\hline Social Skill & -34.437 & 46.167 & -.096 & .418 \\
\hline Extraversion & -2.400 & 18.605 & -.016 & .901 \\
\hline Conscientiousness & .194 & 16.298 & .001 & .992 \\
\hline
\end{tabular}

Note. $R^{2}=.34 ;$ F-test $=4.717 ;\left(p=.001^{\mathrm{c}}\right)$

${ }^{a}$ Standard errors bootstrapped $(\mathrm{BCa})$

${ }^{\mathrm{b}}$ Significance tests bootstrapped (BCa)

${ }^{\mathrm{c}}$ The F-ratio and corresponding $\mathrm{p}$ value are for the parametric, non-bootstrap multiple regression analysis. SPSS does not provide bootstrap results for the ANOVA analysis that tests the overall significance of the model.

As shown in Table 7 above, the overall regression model was significant $(F(7,63)=4.794, p=.001)$, accounting for $34 \%$ of the variance in the dependent variable. Looking closely at the coefficients of each variable in the table, only three variables are found to significantly predict the proportion of pragmatic interpretations: neuroticism $(t(63)=$ $3.926, p<.001$, bootstrap estimates) and communication $(t(63)=2.869, p=.008$, bootstrap estimates) being both positive and significant, and openness $(t(63)=-2.077, p=.015$, bootstrap estimates) being negative and significant. These results suggest that those who scored high in neuroticism (i.e., anxiety) and in communication (i.e., autisticlike) tended have significant delays in processing the pragmatic interpretations of scalar implicatures, whereas those who scored high in openness tended to be faster in computing the implicature.

\section{Discussion}

\section{Rate of rejections of under-informative sentences}

The present study has examined the extent to which L2 learners with modest and competent level of English are sensitive to under-informative sentences. The participants were required to read infelicitous sentences such as "Some parrots are birds" and judge whether they are true or false. Participants' rejections to these under-informative sentences meant that the participants are sensitive to the pragmatic implicature some-but-not-all embedded in the quantifier some, whereas participants' acceptances to these under-informative sentences meant that the participants are not sensitive to the pragmatic meaning embedded in the quantifier some and they treat some as some and possibly all. The results of the study revealed that the participants with a proficiency advantage were significantly more sensitive to the pragmatic meaning of Some than those with weaker English proficiency. Prima facie, these results do not converge with the proposition that scalar inferences are generated by default and their computation is not problematic to L2 learners regardless of their proficiency level. (e.g., [45-47, 50]). If scalar implicature computation is really automatic and not effortful to L2 learners, then our data should show that the participants with modest English are able to make pragmatic interpretations in comparable proportions to those with competent English. However, this was not the case. Our data provided evidence that the participants with modest English were less sensitive to the infelicity embedded in 
under-informative sentences compared to their more competent peers, and thus the increased sensitivity to underinformative sentences among L2 learners seem to be strongly linked to their increased language proficiency (e.g., [68]). Similar empirical evidence was also recently obtained by Mazzaggio et al. [37] with Italian adult speakers of English tested in a sentence evaluation task using time constraints.

In discussing why our results do not corroborate several previous findings in L2 context, we mainly attribute that to differences in the methodological paradigm. Our study used an online sentence verification paradigm that requires the participants to judge the truth-value of under-informative sentences as quickly as possible, whereas previous studies on L2 adults used offline paper-and-pencil tests in which the participants seemed to rely on self-paced reading times that allow one to elaborate their reasoning of the meaning of the statement before giving their final answer. In other words, because of the freely available time in the task, the participants were given the opportunity to cautiously adjust their comprehension of the under-informative statements before giving their final judgment, and therefore, they appeared more pragmatic than logical in these previous offline studies.

A stronger piece of evidence in support of this view comes from reaction time studies (e.g., [2, 19, 20]). For instance, Bott and Noveck [2] manipulated the cognitive resources available to participants by placing them into two corresponding conditions, the Long Condition and Short Condition. These two conditions varied in the time available for participants to make a response, where in the Long condition participants were given a relatively long time to respond (3s), whereas in the Short condition they were given a relatively short time to respond $(900 \mathrm{~ms})$. Bott and Noveck found evidence that participants derived fewer inferences when the cognitive resources were rendered limited in the Short condition, whereas they were more successful at interpreting the implicature when they were given enough time to allow them draw upon the resources that have at their disposal (Long condition) (see [19, 20, 25], for similar arguments).

Another possible explanation can be linked to the qualitative difference in reasoning inferences in online and offline tasks. This proposition can be indirectly supported by demonstrations obtained from research on second language sentence processing [58, 60, 69]. For instance, Roberts and colleagues [60] found that L2 learners have difficulty in updating the discourse information in online tasks, but they demonstrated a native-like behavior in offline tasks (see also [70]). Reverse patterns have also been reported (e.g., [61, 71]); for example, Cho [61] found that L1-Korean L2English speakers are sensitive to the inappropriate use of articles in an online self-paced task, but they exhibited inferior performance in untimed acceptability judgment task. These discrepancies between online and offline tasks were mainly attributed to differences in the type of knowledge L2 learners draw on these tasks, specifically whether it is implicit or explicit knowledge [72,73]. This being so, it possible that the discrepancy between our current online results and those of the previous offline studies were a proxy of task-related effects. Our online sentence judgment task may have assessed the implicit knowledge of the participants, whereas the previous offline investigations may have assessed participants' explicit knowledge. Our results may raise important methodological considerations related to the influence of linguistic task on L2 performance in pragmatics and thus to the validity of result interpretations.

\section{Processing time of pragmatic interpretations of scalar implicatures}

There is a large body of work that has focused on how scalar inferences are given rise to before their manifestation in the form of judgment response. Reports are mainly split into two camps; one is placing emphasis on the proposition that sentences with scalar implicatures carry processing costs (e.g., [2, 12, 18, 20,31, 35, 37, 74]), and the other placing emphasis on that pragmatic processing is not associated with any cognitive load (e.g., [3, 15, 16, 47, 75]). These results were to a large extent discussed in the light of two psychological theories which envisage opposing views about how logical and pragmatic interpretations unfold prior to their manifestation in the form of a response: the default theory [10] and the relevance theory [11]. While the default theory predicts more processing times for the logical meaning than the pragmatic meaning, the relevance theory predicts the opposite: the pragmatic meaning takes 
a longer time to process than the logical meaning because it is generated in a second step after the logical meaning was processed.

Our results seem to support the relevance theory account which argues that interpreting under-informative sentences takes a longer time to process than the logical interpretation: the two proficiency groups took significantly longer times to process the pragmatic interpretation some but not all than the logical interpretation some and possibly all. There was no evidence in the data that the participants needed more time to arrive at a true response for the T1 sentences than a false response. The reaction time required for a logical response was faster than the reaction time required for a pragmatic response. Similar to Bott and Noveck [2], the results further revealed that the pragmatic responses were slower than all the responses in the control sentences T2, T3, T4, T5, and T6, which suggests that processing T1-pragmatic interpretations is characteristically different from all other control sentences.

Our study compared the time taken to make pragmatic interpretations among the modest and competent English group. The results revealed that there was a significant difference in their processing times: the pragmatic responding among the modest English group was significantly slower than that in the competent English group, and thus supports the idea that computing scalar inferences is more cognitively demanding for modest users of English than competent users of English. It is worth stating that these results do not converge with other results obtained from a similar online study [47]. Lin [47] investigated scalar implicatures triggered by some and found that intermediate Mandarin learners of English were faster at interpreting some as some but not all than some and possibly all. In three experiments, Lin started off the linguistic task with this sample preamble "John has many dictionaries. Some of the dictionaries are used" and then asked the participants to read target experimental sentences such as "Some but not all of John's dictionaries are used" or "Some and possibly all of John's dictionaries are used" that the participants had to evaluate and judge whether they are True or False. Lin found that the participants' acceptances to "Some but not all" were significantly more frequently than those given to "Some and possibly all" (85\% vs 15\%). Their rejections of "Some and possibly all" were also significantly slower than their acceptances of "Some but not all". Lin explained these results in the light of the default account which proposes that the pragmatic interpretations arrive automatically without a cognitive load. Lin's findings are paradoxical to our results and it is little perplexing about how to explain the underlying reasons(s). However, a possible explanation for this discrepancy is the testing material and design. In Lin's study design, the participants were given the pragmatic interpretation some but not all of John's dictionaries are used and the logical interpretation some and possibly all in an explicit multiple-choice form and therefore the participants may have relied more on systematic strategies in their final judgments. It is also possible that the verification procedures the were consumed to make the truth/ false judgment in Lin's design were possibly characteristically different from the verification procedures needed to calculate for the implicit pragmatic enrichment in categorical test sentences. Nevertheless, these suggestions remain speculative and thus could be exceedingly imprecise.

\section{Relationship between personality traits and rate of rejections of under-informative sentences}

This study assessed the relationship between participants' personality traits and the rate of pragmatic interpretations of scalar implicatures. This investigation was mainly motivated by the proposition that the variability in responding to under-informative statements might be triggered by a decision that is made at a meta-linguistic level: whether to accept and reject an under-informative statement is possibly dependent upon personality and cognitive flexibility [26] (see also [41, 76]). Our results seem to support this view: participants' personality profile has, in part, modulated their tendency to derive pragmatic interpretations. In the modest English group, the results revealed two variables that correlate with the rate of pragmatic interpretations; namely, the trait attention to detail being negatively and significantly correlated with participants' pragmatic interpretations and the trait Systemizing being positively and significantly correlated. These results denote that those with autistic-like attention to detail tended to have weaker tendencies to draw the pragmatic interpretation, whereas those with stronger systemizing skills tended to have a stronger drive towards making more pragmatic interpretations of scalar implicatures. Similar effects in the competent 
English group were also observed: the two autistic traits Social Skill and Imagination are significantly and negatively correlated with the rate of pragmatic interpretations. Thus, those who had autistic-like traits tended to be more literal in their interpretations of scalar implicatures, as the Autism Spectrum Disorders' interpretations are known to be [7779] .

Our findings seem to converge with a recent study that did find a relationship between participants' personality traits and the proportion of scalar implicature interpretation [80]. Yang et al. examined the comprehension of scalar implicatures triggered by the quantifier some in a story-sentence matching task and found that those with greater sociopragmatic abilities (as measured by the AQ) had higher sensitivity to pragmatic violations, and thus evidence that lends support to accounts arguing about the likelihood personality traits modulate the sensitivity to under-informative statements (e.g., [33, 81]). Our results are also in tandem with recent findings obtained from an ERP study [32]. Barbet and Thierry [32] were the first to find a link between the systemizing skill and participants' sensitivity to scalar implicatures. They found that participants who score high on trait systemizing are less likely to agree with statements that do not describe reality with high accuracy, and therefore, to reject more under-informative sentence more frequently. This positive link between systemizing and pragmatic intolerance to pragmatic violations also supports similar findings reported on individuals with high-functioning autism and Asperger's syndrome, including children [82] and adults [83].

\section{Relationship between personality traits and processing time of pragmatic interpretations}

The present study assessed the relationship between personality traits and the time taken to process pragmatic interpretations of scalar implicatures among L2 adults with modest and competent level of English. In both groups, the results revealed that the trait neuroticism was associated with delays in the reaction times taken to respond pragmatically to $\mathrm{T} 1$ sentences. The results also indicated that the competent participants who had a low score on the autistic trait communication and high on trait openness tended to make faster reaction times, and thus evidence supporting previous experimental results obtained from ERP studies (e.g., [41, 43]). For instance, Nieuwland and colleagues [41] found that participants with a low score on the communication AQ sub-scale (referred to as "pragmatically skilled participants") were more sensitive to pragmatic violations as indexed by the N400 event-related potential (ERP). Zhao et al. [43] also found that acoustically presented under-informative sentences (e.g., "Some tigers have tails") elicited a prominent ERP effect in participants with a low score on the Communication and Social Skill sub-scales ("the high pragmatic ability group"), but there was no significant mismatch negativity effect (MMN) for the low pragmatic ability group. Zhao and colleagues suggested that the pragmatic ability of the individual may affect the mechanism of scalar implicature processing where more automatic processing is likely to occur with those individuals with higher pragmatic abilities.

In discussing the reason why trait neuroticism was significantly and positively correlated with the time taken to make pragmatic interpretations of scalar implicatures in the two proficiency groups, surprisingly there is no speculation on this finding in scalar implicature research. However, the literature on personality traits and social psychology suggests that the trait neuroticism is characterized by feelings of anxiety, worry, fear, depression, and self-consciousness [84]. In the field of cognitive science, the trait neuroticism is associated with variability in emotional and cognitive processes [85, 86]. Individuals who score high on trait neuroticism tend to be less flexible in their cognitive processes and they are slower when processing non-verbal processing tasks than verbal processing tasks [87]. The non-verbal tasks are also more reliant on executive functions and attentional resources that are more vulnerable to be usurped by irrelevant thoughts related to worry and anxiety [88]. The results of the present study seem to be consistent with these aforementioned explanations. The participants who scored high in neuroticism tended to exhibit increased reaction times in the pragmatic task; and importantly, this association between trait neuroticism and increased reaction times was also only evident in T1-Pragmatic sentences. There was no significant relationship between the trait neuroticism and the time taken to respond to the control sentences. 
However, one may wonder why the effect of neuroticism was exclusive to the time taken to respond to T1-Pragmatic and not to the other control sentences? A potential explanation for this observed phenomenon is that the effect of neuroticism appears mainly in cognitive tasks that place significant demands on cognitive resources, especially the central executive function [88]. Neuroticism increases "the allocation of attention to threat-related stimuli, and to deciding how to respond in the anxiety-provoking circumstances", and therefore consumes the limited attentional resources of working memory that they in turn become less available for concurrent processing task. The T1-Pragmatic is the only critical test sentence in the experiment that comes with increased reasoning attention and cognitive demands compared to control sentences. The reaction time data of the study has previously revealed that T1-pragmatic is accompanied by cognitive costs that makes is characteristically different from the other control sentences. Therefore, the participants who had a high score on neuroticism (i.e., anxiety, or worry in the large sense) may have allocated extra cautionary attention onto deciding which interpretation to make, logical or pragmatic, that resulted in increased reaction times compared to their less-neurotic peers.

It is also worth noting that the neuroticism scores did not affect the proportion of pragmatic interpretations of the participants as was given in the correlational analyses of the study: the effect of trait neuroticism was only orthogonal to the processing time of these pragmatic interpretations. According to the attentional control theory [88], an approach to anxiety and cognition, low- and high-anxious individuals may have comparable performance effectiveness (quality of performance/accuracy), but not similar response time efficiency. The results of the present study converge with these predictions: the low- and high-neurotic participants provided comparable proportions of pragmatic interpretations, but they exhibited significant differences in response time. There are also several studies on other domains that provided similar evidence, including studies on verbal reasoning [89]; spatial reasoning [90]; grammatical reasoning [91], and reading comprehension [92], inter alia; and therefore, a large of body of supporting evidence.

\section{Conclusions}

The present study has investigated scalar implicature computation among L2 adults, specifically how individual differences in second language skills and personality traits would modulate scalar implicature comprehension. Our results provided evidence that implicature comprehension is influenced by participants' L2 proficiency level and some other personality traits. The participants with modest English proficiency were less sensitive to implicatures compared to their competent peers, i.e., the pragmatic ability among L2 adults is increased with the increase of their L2 proficiency. The results also revealed that the two groups took significantly more time to process the pragmatic interpretation than the logical interpretation. The time taken to process the pragmatic interpretation was also significantly slower among those with modest English than competent English, and therefore evidence denoting that computing not all for some was cognitively effortful to participants with lower linguistic abilities. The results also revealed that those with autistic-like characteristics tended to literal in their interpretations of scalar implicatures and slower in their processing times. These results provide useful and breakthrough insights into how bilingual adults process scalar implicatures in their second language, and thus considerations to the processing theories in experimental pragmatics and second language acquisition.

Our study has few limitations and implicatures for future research. First, our study used a sentence verification paradigm and there are views which suggest that the response times obtained from these verification tasks may not completely reflect the general features of the inferential process that occurred before an overt response was made, but rather to features attributable to embedded negation in some (e.g.,[27]), the decision to disambiguate the implicatures (e.g.,[25]), the theory of mind (e.g., [23]), inter alia. Future studies on bilingual adults may need to use other online testing measures, such the eye tracking technique (e.g., $[18,93])$ and the event-related potential (e.g., $[32,43])$. These methods can provide stronger insights into the processes involved in scalar implicature comprehension. 
Second, this study also asked the participants to judge the infelicity of the under-informative statements in an artificial context. However, a general limitation of testing some in isolation is the absence of a more natural communicative setting that provides information about whether or not the implicature is relevant, and therefore a better approach in which one can examine how individuals would interpret some in scenarios akin to everyday language situations [80, 94, 95]. Artificial contexts may also discourage the participants to project their own personality characteristics and their own attitudes which may in turn modulate their comprehension and interpretation of critical utterances [76]. Future studies may need to examine implicature comprehension in contextualized settings. There is infant evidence which demonstrates that context modulates implicature understanding $[13,96]$.

Third, the present study has only focused on scalar implicatures triggered by the quantifier some. However, some recent investigations on scalar implicature processing recommend testing a broad range of scalar words the differ in their scalarity, viz, positively scalar words (e.g., <might, must>, <some, all>, and <most, all>) vs negatively scalar words (e.g., <low, empty>, <scarce, absent>) [27, 30]. According to van Tiel and colleagues [27], the scalarity of a word determines the polarity of the corresponding scalar inference, i.e., the positively scalar word some gives rise to the negative scalar inference not all, whereas the negatively scalar word not all gives rise to the positive scalar inference not-none, or, equivalently, to some. This being so, it is possible that the negation embedded in the positively scalar words makes the inferential process computationally more complex, and thus artificially inflates the processing times of scalar inferences. There is still little work in this direction and therefore an interesting venue left open for future research.

\section{Acknowledgments}

The authors would like to thank Ira Noveck for some valuable feedback on an earlier version of this manuscript. This study was supported by the Malaysian International Scholarship awarded to the first author Ahmed Khorsheed. The authors Ahmed Khorsheed, Sabariah Md Rashid, and Vahid Nimehchisalem were also supported by a research grant funded by the Research Management Centre at Universiti Putra Malaysia (reference: GP-IPS/2018/9651200). 


\section{References}

1. Grice HP. Logic and conversation. Speech acts: Brill; 1975. p. 41-58.

2. Bott L, Noveck IA. Some utterances are underinformative: The onset and time course of scalar inferences. Journal of Memory and Language. 2004;51(3):437-57. doi: 10.1016/j.jml.2004.05.006.

3. Breheny R, Katsos N, Williams J. Are generalised scalar implicatures generated by default? An on-line investigation into the role of context in generating pragmatic inferences. Cognition. 2006;100(3):434-63. doi: 10.1016/j.cognition.2005.07.003.

4. Grice HP. Studies in the Way of Words: Harvard University Press; 1989.

5. Gazdar G. Pragmatics: Implicature, Presupposition and Logical Form: Academic Press; 1979.

6. Horn LR. On the Semantic Properties of Logical Operators in English: Indiana University Linguistics Club; 1976.

7. Noveck IA. When children are more logical than adults: Experimental investigations of scalar implicature. Cognition. 2001;78(2):165-88. doi: 10.1016/S0010-0277(00)00114-1.

8. Carston R. Thoughts and Utterances: Oxford: Blackwell; 2002.

9. Noveck I. Experimental pragmatics: The making of a cognitive science: Cambridge University Press; 2018.

10. Levinson SC. Presumptive meanings: The theory of generalized conversational implicature: The MIT Press; 2000.

11. Sperber D, Wilson D. Précis of Relevance: Communication and Cognition. Behavioral and Brain Sciences. 1987;10(04):697-. doi: 10.1017/s0140525x00055345.

12. Tomlinson JM, Bailey TM, Bott L. Possibly all of that and then some: Scalar implicatures are understood in two steps. Journal of Memory and Language. 2013;69(1):18-35. doi: 10.1016/j.jml.2013.02.003.

13. Barbet C, Thierry G. When some triggers a scalar inference out of the blue. An electrophysiological study of a Stroop-like conflict elicited by single words. Cognition. 2018;177(March):58-68. doi: 10.1016/j.cognition.2018.03.013.

14. Degen J, Tanenhaus MK. Availability of Alternatives and the Processing of Scalar Implicatures: A Visual World Eye-Tracking Study. Cognitive Science. 2016;40(1):172-201. doi: 10.1111/cogs.12227.

15. Politzer-Ahles S, Fiorentino R. The Realization of Scalar Inferences: Context Sensitivity without Processing Cost. PLoS ONE. 2013;8(5). doi: 10.1371/journal.pone.0063943.

16. Grodner DJ, Klein NM, Carbary KM, Tanenhaus MK. "Some," and possibly all, scalar inferences are not delayed: Evidence for immediate pragmatic enrichment. Cognition. 2010;116(1):42-55. doi: 10.1016/j.cognition.2010.03.014.

17. Heyman T, Schaeken W. Some diferences in some: Examining variability in the interpretation of scalars using latent class analysis. Psychologica Belgica. 2015;55(1):1-18. doi: $10.5334 / p b . b c$. 
18. Huang YT, Snedeker J. Some inferences still take time: Prosody, predictability, and the speed of scalar implicatures. Cognitive Psychology. 2018;102(January):105-26. doi: 10.1016/j.cogpsych.2018.01.004.

19. Bott L, Bailey TM, Grodner D. Distinguishing speed from accuracy in scalar implicatures. Journal of Memory and Language. 2012;66(1):123-42. doi: 10.1016/j.jml.2011.09.005.

20. De Neys W, Schaeken W. When people are more logical under cognitive load dual task impact on scalar implicature. Experimental Psychology. 2007;54(2):128-33. doi: 10.1027/1618-3169.54.2.128.

21. Noveck IA, Posada A. Characterizing the time course of an implicature: An evoked potentials study. Brain and Language. 2003;85(2):203-10. doi: 10.1016/S0093934X(03)00053-1.

22. Apperly IA, Back E, Samson D, France L. The cost of thinking about false beliefs : Evidence from adults ' performance on a non-inferential theory of mind task. 2008;106:1093-108. doi: 10.1016/j.cognition.2007.05.005.

23. Breheny R, Ferguson HJ, Katsos N. Taking the epistemic step: Toward a model of on-line access to conversational implicatures. Cognition. 2013;126(3):423-40. doi: 10.1016/j.cognition.2012.11.012.

24. Fairchild S, Papafragou A. The Role of Executive Function and Theory of Mind in Pragmatic Computations. 2021;45(2):e12938. doi: 10.1111/cogs.12938.

25. Marty PP, Chemla E. Scalar implicatures: Working memory and a comparison with only. Frontiers in Psychology. 2013;4(JUL):1-12. doi: 10.3389/fpsyg.2013.00403.

26. Katsos N, Bishop DVM. Pragmatic tolerance: Implications for the acquisition of informativeness and implicature. Cognition. 2011;120(1):67-81. doi: 10.1016/j.cognition.2011.02.015.

27. van Tiel B, Pankratz E, Sun C. Scales and scalarity: Processing scalar inferences. Journal of Memory and Language. 2019;105(July 2018):93-107. doi: 10.1016/j.jml.2018.12.002.

28. Rips LJ. Quantification and semantic memory. Cognitive Psychology. 1975;7(3):307-40. doi: 10.1016/0010-0285(75)90014-6.

29. Gotzner N, Solt S, Benz A. Scalar diversity, negative strengthening, and adjectival semantics. Frontiers in Psychology. 2018;9(SEP):191-203. doi: 10.3389/fpsyg.2018.01659.

30. van Tiel B, Pankratz E. Adjectival polarity and the processing of scalar inferences. Glossa: a journal of general linguistics. 2021;6(1). doi: 10.5334/gjgl.1457.

31. Antoniou K, Cummins C, Katsos N. Why only some adults reject under-informative utterances. Journal of Pragmatics. 2016;99:78-95. doi: 10.1016/j.pragma.2016.05.001.

32. Barbet C, Thierry G. Some alternatives? Event-related potential investigation of literal and pragmatic interpretations of some presented in isolation. Frontiers in Psychology. 2016;7(SEP). doi: 10.3389/fpsyg.2016.01479.

33. Mazzaggio G, Surian L. A diminished propensity to compute scalar implicatures is linked to autistic traits. Acta Linguistica Academica. 2018;65(4):651-68. doi: 10.1556/2062.2018.65.4.4. 
34. Reboul AC, Stateva P. Editorial: Scalar Implicatures. 2019;10(1767). doi: 10.3389/fpsyg.2019.01767.

35. Dieussaert K, Verkerk S, Gillard E, Schaeken W. Some effort for some: Further evidence that scalar implicatures are effortful. Quarterly Journal of Experimental Psychology. 2011;64(12):2352-67. doi: 10.1080/17470218.2011.588799.

36. Antoniou K, Veenstra A, Kissine M, Katsos N. How does childhood bilingualism and bidialectalism affect the interpretation and processing of pragmatic meanings? Bilingualism. 2020;23(1):186-203. doi: 10.1017/S1366728918001189.

37. Mazzaggio G, Panizza D, Surian L. On the interpretation of scalar implicatures in first and second language. Journal of Pragmatics. 2021;171:62-75. doi: 10.1016/j.pragma.2020.10.005.

38. Van Tiel B, Van Miltenburg E, Zevakhina N, Geurts B. Scalar diversity. Journal of Semantics. 2016;33(1):137-75. doi: 10.1093/jos/ffu017.

39. Baker R, Doran R, McNabb Y, Larson M, Ward G. On the Non-Unified Nature of Scalar Implicature: An Empirical Investigation. International Review of Pragmatics. 2010;1(2):211-48. doi: 10.1163/187730909x12538045489854.

40. Cummins C, Katsos N. The Oxford Handbook of Experimental Semantics and Pragmatics: Oxford University Press; 2019.

41. Nieuwland MS, Ditman T, Kuperberg GR. On the incrementality of pragmatic processing: An ERP investigation of informativeness and pragmatic abilities. Journal of Memory and Language. 2010;63(3):324-46. doi: 10.1016/j.jml.2010.06.005.

42. Baron-Cohen S, Wheelwright S, Skinner R, Martin J, Clubley E. The Autism Spectrum Quotient : Evidence from Asperger syndrome/high functioning autism, males and females, scientists and mathematicians. Journal of Autism and Developmental Disorders. 2001;31(1):5-17. doi: 10.1023/A:1005653411471.

43. Zhao M, Liu T, Chen G, Chen F. Are scalar implicatures automatically processed and different for each individual? A mismatch negativity (MMN) study. Brain Research. 2015;1599(December 2014):137-49. doi: 10.1016/j.brainres.2014.11.049.

44. Alatawi H. Empirical evidence on scalar implicature processing at the behavioural and neural levels: A review. International Review of Pragmatics. 2019;11(1):1-21. doi: 10.1163/18773109-201810011.

45. Slabakova R. Scalar implicatures in second language acquisition. Lingua. 2010;120(10):2444-62. doi: 10.1016/j.lingua.2009.06.005.

46. Snape N. Acquisition of scalar implicatures : Evidence from adult Japanese L2 learners of Acquisition of scalar implicatures : Evidence from adult Japanese L2 learners of English Linguistic Approaches to Bilingualism. 2018;(April). doi: 10.1075/lab.18010.sna.

47. Lin Y. Processing of scalar inferences by Mandarin learners of English: An online measure. PLoS ONE. 2016;11(1):1-27. doi: 10.1371/journal.pone.0145494.

48. Clahsen H, Felser C. Grammatical processing in language learners. Applied Psycholinguistics. 2006;27(1):3-42. doi: 10.1017/S0142716406060024. 
49. Juffs A. Psycholinguistically oriented second language research. Annual Review of Applied Linguistics. 2001;21:207-20. Epub 2002/04/01. doi: 10.1017/S0267190501000125.

50. Dupuy L, Stateva P, Andreetta S, Cheylus A, Déprez V, van der Henst J-B, et al. Pragmatic abilities in bilinguals. Linguistic Approaches to Bilingualism. 2019;9(2):314-40. doi: 10.1075/lab.17017.dup.

51. Bialystok E, Martin MM. Attention and inhibition in bilingual children: Evidence from the dimensional change card sort task. Developmental Science. 2004;7(3):325-39. doi: 10.1111/j.1467-7687.2004.00351.x.

52. Blom E, Küntay AC, Messer M, Verhagen J, Leseman P. The benefits of being bilingual: Working memory in bilingual Turkish-Dutch children. Journal of Experimental Child Psychology. 2014;128:105-19. doi: 10.1016/j.jecp.2014.06.007.

53. Carlson SM, Meltzoff AN. Paper: Bilingual experience and executive functioning in young children. Developmental Science. 2008;11(2):282-98. doi: 10.1111/j.14677687.2008.00675.x.

54. Martin-Rhee MM, Bialystok E. The development of two types of inhibitory control in monolingual and bilingual children. Bilingualism. 2008;11(1):81-93. doi: 10.1017/S1366728907003227.

55. Morales J, Calvo A, Bialystok E. Working memory development in monolingual and bilingual children. Journal of Experimental Child Psychology. 2013;114(2):187-202. doi: 10.1016/j.jecp.2012.09.002.

56. Siegal M, Matsuo A, Pond C, Otsu Y, editors. Bilingualism and cognitive development: Evidence from scalar implicatures. Proceedings of the Eighth Tokyo Conference on Psycholinguistics; 2007: Hituzi Syobo Tokyo.

57. Siegal M, Iozzi L, Surian L. Bilingualism and conversational understanding in young children. Cognition. 2009;110(1):115-22. doi: 10.1016/j.cognition.2008.11.002.

58. Hopp H. The syntaxdiscourse interface in near-native L2 acquisition: Off-line and on-line performance. Bilingualism. 2009;12(4):463-83. doi: 10.1017/S1366728909990253.

59. Hopp H. Ultimate attainment in L2 inflection: Performance similarities between non-native and native speakers. Lingua. 2010;120(4):901-31. doi: 10.1016/j.lingua.2009.06.004.

60. Roberts L, Gullberg M, Indefrey P. Online pronoun resolution in L2 discourse: L1 influence and general learner effects. Studies in Second Language Acquisition. 2008;30(3):333-57. doi: 10.1017/S0272263108080480.

61. Cho J. Online processing and offline judgments of L2-English articles. Linguistic Approaches to Bilingualism. 2020:1-30. doi: 10.1075/lab.18053.cho.

62. Katsos N, Cummins C, Ezeizabarrena MJ, Gavarró A, Kraljević JK, Hrzica G, et al. Crosslinguistic patterns in the acquisition of quantifiers. Proceedings of the National Academy of Sciences of the United States of America. 2016;113(33):9244-9. doi: 10.1073/pnas.1601341113.

63. Baron-Cohen S. Autism, hypersystemizing, and truth. Quarterly Journal of Experimental Psychology. 2008;61(1):64-75. doi: 10.1080/17470210701508749. 
64. Wheelwright S, Baron-Cohen S, Goldenfeld N, Delaney J, Fine D, Smith R, et al. Predicting Autism Spectrum Quotient (AQ) from the Systemizing Quotient-Revised (SQ-R) and Empathy Quotient (EQ). Brain Research. 2006;1079(1):47-56. doi: 10.1016/j.brainres.2006.01.012.

65. Baron-Cohen S. Autism, empathizing-systemizing (es) theory, and pathological altruism. In: Oakley B, Knafo A, Madhavan G, Wilson DS, editors.: Oxford University Press; 2011.

66. Field A. Andy. Discovering Statistics Using IBM SPSS Statistics: London: SAGE PUBN; 2018.

67. McCloskey M, Glucksberg S. Decision processes in verifying category membership statements: Implications for models of semantic memory. Cognitive Psychology. 1979;11(1):1-37. doi: 10.1016/0010-0285(79)90002-1.

68. Xiao F, Taguchi N, Li S. Effects of proficiency subskills on pragmatic development in L2 Chinese study abroad. Studies in Second Language Acquisition. 2019;41(2):469-83. Epub 2018/05/22. doi: 10.1017/S0272263118000128.

69. Ionin T, Choi SH, Liu Q. Knowledge of indefinite articles in L2-English: Online vs. offline performance. Second Language Research. 2019;37(1):121-60. doi: $10.1177 / 0267658319857466$.

70. Gabriele A, Fiorentino R, Covey L. Understanding the symptoms and sources of variability in second language sentence processing. Bilingualism. 2017;20(4):685-6. doi: 10.1017/S1366728916000961.

71. Zufferey S, Mak W, Degand L, Sanders T. Advanced learners' comprehension of discourse connectives: The role of L1 transfer across on-line and off-line tasks. Second Language Research. 2015;31(3):389-411. doi: 10.1177/0267658315573349.

72. Ellis R. Measuring implicit and explicit knowledge of a second language. Implicit and Explicit Knowledge in Second Language Learning, Testing and Teaching. 2005:31-64. doi: 10.21832/9781847691767-004.

73. Godfroid A, Loewen S, Jung S, Park JH, Gass S, Ellis R. Timed and untimed grammaticality judgments measure distinct types of knowledge: Evidence from eye-movement patterns. Studies in Second Language Acquisition. 2015;37(2):269-97. doi: 10.1017/S0272263114000850.

74. Cho J. Memory Load Effect in the Real-Time Processing of Scalar Implicatures. Journal of Psycholinguistic Research. 2020;49(5):865-84. doi: 10.1007/s10936-020-09726-3.

75. Feng S, Cho J. Asymmetries between direct and indirect scalar implicatures in second language acquisition. Frontiers in Psychology. 2019;10(APR):1-17. doi: 10.3389/fpsyg.2019.00877.

76. Feeney A, Bonnefon JF. Politeness and Honesty Contribute Additively to the Interpretation of Scalar Expressions. Journal of Language and Social Psychology. 2013;32(2):181-90. doi: 10.1177/0261927X12456840. 
77. Mazzaggio G, Foppolo F, Job R, Surian L. Ad-hoc and scalar implicatures in children with autism spectrum disorder. Journal of Communication Disorders. 2021;90. doi: 10.1016/j.jcomdis.2021.106089.

78. Schaeken W, Haeren MV, Bambini V. The understanding of scalar implicatures in children with autism spectrum disorder: Dichotomized responses to violations of informativeness. Frontiers in Psychology. 2018;9(JUL). doi: 10.3389/fpsyg.2018.01266.

79. Pastor-Cerezuela G, Yllescas JCT, González-Sala F, Montagut-Asunción M, FernándezAndrés MI. Comprehension of generalized conversational implicatures by children with and without autism spectrum disorder. Frontiers in Psychology. 2018;9(MAR). doi: 10.3389/fpsyg.2018.00272.

80. Yang X, Minai U, Fiorentino R. Context-sensitivity and individual differences in the derivation of scalar implicature. Frontiers in Psychology. 2018;9(SEP):1-14. doi: 10.3389/fpsyg.2018.01720.

81. Reboul AC, Stateva P. Editorial : Scalar Implicatures. 2019;10(July):10-2. doi: 10.1111/cogs.12171.

82. Chevallier C, Wilson D, Happé F, Noveck I. Scalar inferences in autism spectrum disorders. Journal of Autism and Developmental Disorders. 2010;40(9):1104-17. doi: 10.1007/s10803010-0960-8.

83. Pijnacker J, Hagoort P, Buitelaar J, Teunisse JP, Geurts B. Pragmatic inferences in highfunctioning adults with autism and Asperger syndrome. Journal of Autism and Developmental Disorders. 2009;39(4):607-18. doi: 10.1007/s10803-008-0661-8.

84. John OP, Srivastava S. The Big Five trait taxonomy: History, measurement, and theoretical perspectives. Handbook of personality: Theory and research. 1999;2(1999):102-38.

85. Carver CS, Sutton SK, Scheier MF. Action, emotion, and personality: Emerging conceptual integration. Personality and social psychology bulletin. 2000;26(6):741-51.

86. Gross JJ, Sutton SK, Ketelaar T. Relations between affect and personality: Support for the affect-level and affective-reactivity views. Personality and social psychology bulletin. 1998;24(3):279-88.

87. Hale S, Myerson J. Experimental evidence for differential slowing in the lexical and nonlexical domains. Aging, Neuropsychology, and Cognition. 1996;3(2):154-65.

88. Eysenck MW, Derakshan N, Santos R, Calvo MG. Anxiety and cognitive performance: Attentional control theory. Emotion. 2007;7(2):336-53. doi: 10.1037/1528-3542.7.2.336.

89. Darke S. Effects of Anxiety on Inferential Reasoning Task Performance. Journal of Personality and Social Psychology. 1988;55(3):499-505. doi: 10.1037/0022-3514.55.3.499.

90. Markham R, Darke S. The effects of anxiety on verbal and spatial task performance. Australian Journal of Psychology. 1991;43(2):107-11.

91. Derakshan N, Eysenck MW. Working Memory Capacity in High Trait-anxious and Repressor Groups. Cognition and Emotion. 1998;12(5):697-713. doi: 10.1080/026999398379501. 
92. Calvo MG, Carreiras M. Selective influence of test anxiety on reading processes. British Journal of Psychology. 1993;84(3):375-88.

93. Politzer-Ahles S, Matthew Husband E. Eye movement evidence for context-sensitive derivation of scalar inferences. Collabra: Psychology. 2018;4(1):1-13. doi: 10.1525/collabra.100.

94. Degen J. Processing Scalar Implicatures: What Role Does the Question of Default Play for the Debate Between (Neo-)Griceanism and Relevance Theory? Publications of the Institute of Cognitive Science. 2007;3.

95. Degen J, Goodman ND. Lost your marbles? The puzzle of dependent measures in experimental pragmatics. Proceedings of the 36th Annual Conference of the Cognitive Science Society. 2014:397-402.

96. Sikos L, Kim M, Grodner DJ. Social context modulates tolerance for pragmatic violations in binary but not graded judgments. Frontiers in Psychology. 2019;10(MAR). doi: 10.3389/fpsyg.2019.00510. 


\section{Supporting information}

Appendix A. The categories and exemplars of the truth-value judgment task 